\title{
Primeiro registro de Glycaspis brimblecombei Moore 1964, (Hemiptera: Psyllidae) em Eucalipto no Estado de Santa Catarina, Brasil
}

\author{
First record of Glycaspis brimblecombei Moore 1964, (Hemiptera: Psyllidae) in Eucalyptus \\ in Santa Catarina State, Brazil.
}

\author{
Junir Antonio Lutinski ${ }^{1}$ Cladis Juliana Lutinski ${ }^{2}$ Flávio Roberto Mello Garcia ${ }^{3}$
}

\begin{abstract}
RESUMO
Conhecido como psilídeo-de-concha, Glycaspis brimblecombei é um inseto sugador de origem australiana e ataca várias espécies de eucalipto. Sua presença no Brasil foi registrada pela primeira vez no Estado de São Paulo em junho de 2003. Posteriormente, sua ocorrência foi registrada também para os Estados de Minas Gerais, Goiás, Paraná e Mato Grosso do Sul. As ninfas possuem coloração amarelada e encontramse protegidas sob pequenas conchas enquanto os adultos, com coloração marrom-alaranjado a amarelo-esverdeado, medem cerca de três milímetros de comprimento. Dentre os principais danos que causam às plantas estão a queda prematura das folhas, redução da área fotossintética e superbrotamento. Em alguns casos, pode levar à morte da planta. No Estado de Santa Catarina, o G. brimblecombei foi encontrado atacando algumas plantas de Eucalyptus tereticornis localizadas no pátio de uma empresa no perímetro urbano da cidade de Chapecó.

Palavras-chave: Psilídeo-de-concha, insetos de Santa Catarina, pragas florestais.
\end{abstract}

- NOTA-

\section{ABSTRACT}

Known as Red gum lerp psyllid, Glycaspis brimblecombei is a sucker insect of Australian origin whose attacks several eucalyptus species. Its presence in Brazil was reported for the first time in the São Paulo State in June, 2003. Later, its occurrence was also registered in Minas Gerais, Goiás, Paraná and Mato Grosso do Sul States. The nymphs possess yellowish color and they are protected under small shells while the adults have brown-orange to yellow-greenish color, and about three milimeters. Among the main damages that causes to the plants are the premature leaves fall and reduction of the photosynthetic area. In some cases it can occurs plant death. In Santa Catarina State it was found attacking some trees of Eucalyptus tereticornis in the courtyard of a company in the urban perimeter of the Chapecó town.

Key words: Red gum lerp psyllid, insects of Santa Catarina State.

De origem Australiana, o eucalipto foi introduzido no Brasil na segunda metade do século XIX com o objetivo de ajudar na produção de dormentes para as linhas férreas que se instalavam no país. Atualmente, o país possui a maior área plantada de eucaliptos do mundo com mais de três milhões de hectares plantados. O eucalipto produzido no Brasil destina-se basicamente à produção de celulose, de papel e ao carvão que abastece as siderúrgicas. O eucalipto também é destinado à indústria moveleira e à extração de óleos essenciais (MCT, 2005).

O Estado de Santa Catarina possui cerca de $10 \%$ das florestas plantadas do país, gerando neste setor cerca de 90 mil postos de trabalho de forma direta

${ }^{1}$ Universidade Comunitária Regional de Chapecó (UNOCHAPECÓ), Programa de Mestrado em Ciências Ambientais. Lab. de Entomologia, CP. 747, 89809-000, Chapecó, SC, Brasil. E-mail: lutinski@ibest.com.br. Autor para correspondência.

${ }^{2}$ UNOCHAPECÓ, Centro de Ciências Agroambientais e de Alimentos, CP. 747, 89809-000, Chapecó, SC, Brasil. E-mail: lutinski@bol.com.br.

${ }^{3}$ Laboratório de Entomologia, UNOCHAPECÓ, Centro de Ciências Agroambientais e de Alimentos, CP. 747, 89809-000, Chapecó, SC, Brasil. E-mail: flaviog@unochapeco.edu.br. 
e reunindo cerca de cinco mil empresas. O Estado é o terceiro maior produtor de papel e celulose do país e o foi o maior exportador de móveis em 2003 com cerca de $60 \%$ do volume exportado. Aproximadamente $10 \%$ desta produção no Estado é proveniente de plantações de eucalipto (CEPA/SC, 2004).

A produção de eucalipto no Brasil, poderá vir a sofrer perdas consideráveis com a introdução recente do psilídeo Glicaspis brimblecombei Moore 1964. Esta praga foi responsável por grandes perdas após sua introdução nos Estados Unidos e no México (WILCKEN et al., 2003).

Originário da Austrália, a forma de introdução deste inseto no Brasil é incerta, porém, é provável que chegou ao país via aeroportos. Os danos causados por esta praga foram inicialmente detectados no Estado de São Paulo, em meados de 2003, quando também foi constatada a sua ocorrência atacando plantações de Eucalyptus grandis. (WILCKEN et al., 2003). Atualmente já foi detectada a sua presença também nos Estados do Paraná, Minas Gerais e Goiás atacando também outras espécies de eucalipto como Eucalyptus camadulensis e Eucalyptus tereticornis entre outras (EMBRAPA, 2004).

G. brimblecombei é um inseto pertencente à ordem Hemiptera e à família Psyllidae. De tamanho diminuto, mede entre um a cinco milímetros de comprimento, assemelha-se a pequenas cigarrinhas e apresenta hábito alimentar sugador. Tem preferência por brotações e ponteiros. Nos primeiros instares, as ninfas apresentam coloração amarelada enquanto, no último, a coloração do abdômen e dos primórdios das asas é mais escura. A espécie em geral apresenta adultos com coloração variando entre cinza-alaranjada a amarelo-esverdeada e dois pares de asas. Os ovos são de coloração avermelhada. Quanto à biologia, apresentam reprodução sexuada, sendo que as fêmeas ovipositam em folhas abertas (DREISTADT \& DAHLSTEN, 2001). Devido à produção de pequenos cones brancos sobre as folhas que se assemelham a conchas brancas, sob os quais se desenvolvem as ninfas, vem o nome psilídeo-de-concha. Outra característica dessa praga é sua rápida capacidade de dispersão no ecossistema florestal, sendo considerada atualmente praga de importância econômica (SÁ \& WILCKEN, 2004).

Dentre os principais danos que esta praga causa às plantas de eucalipto, destacam-se a redução e deformação do limbo foliar, a redução da área fotossintética devido à cobertura das folhas pela fumagina e conchas, a queda prematura de folhas, o superbrotamento, a seca de ponteiros e em casos de ataques severos podem ocasionar a morte da planta (EMBRAPA, 2004).

O manejo integrado pode ser uma alternativa no combate à praga. SÁ \& WILCKEN (2004) descrevem o parasitóide Psyllaephagus bliteus (Hymenoptera: Encyrtidae) parasitando ninfas de $\boldsymbol{G}$. brimblecombei sobre folhas de eucalipto.

Este parasitóide pode proporcionar um controle de até $80 \%$ e juntamente com outros inimigos naturais como aranhas, crisopídeos, joaninhas, larvas de sifídeos, percevejos predadores e fungos entomopatogênicos podem proporcionar um manejo integrado eficaz (EMBRAPA, 2004).

No Estado de Santa Catarina, G. brimblecombei foi encontrado inicialmente em outubro de 2004 em uma plantação de E. tereticornis localizada no pátio de uma empresa no perímetro urbano da cidade de Chapecó (2706'155”S, 5240’748”W). Posteriormente, a praga foi encontrada em outros pontos da cidade. A provável forma de dispersão da praga até a região foi via transporte rodoviário. Na área em que foi encontrada, é grande a movimentação de caminhões, que transportam produtos para regiões, onde o psilídeo já foi previamente encontrado. Ao retornar, estes caminhões transportam estrados de madeira, que podem ter servido de abrigo para os adultos deste inseto.

Os espécimes de $\boldsymbol{G}$. brimblecombei foram identificados a partir das ilustrações e da caracterização descrita por WILCKEN et al.(2003), sendo que o material encontra-se depositado no Laboratório de Entomologia da Universidade Comunitária Regional de Chapecó, SC. Não foi constatada uma intensa infestação do inseto nas plantas estudadas e, por isso, os danos observados resumem-se, até o momento, a folhas de ponteiros mal formadas e a queda de folhas.

$\mathrm{Na}$ região oeste do Estado de Santa Catarina, existem grandes áreas de plantações de eucalipto que visam principalmente à exploração da madeira para a construção civil e à alimentação das caldeiras das várias agroindústrias instaladas na região. Não existem estimativas convergentes sobre a área de eucalipto plantada nesta região uma vez que houve um significativo aumento, principalmente em pequenas propriedades rurais, onde o reflorestamento se tornou uma alternativa à crise que assola este setor nos últimos anos. Entretanto, de acordo com os dados da CEPA/ SC (2004), a produção anual de lenha de eucalipto, na região oeste, é de aproximadamente quatro milhões de $\mathrm{m}^{3}$. Ações de manejo e controle preventivo da praga se fazem necessários para que esta não traga à região os prejuízos verificados em outras locais. 


\section{REFERÊNCIAS}

CEPA/SC. Síntese anual da agricultura de Santa Catarina. Florianópolis: Secretaria de Estado da Agricultura e Política Rural, 2004. 377p.

DReistadT, S.H.; DAhlsten, D.L. Pest notes: Psyllids Oakland, University of California. Agriculture and Natural Resource. 2001. Referência 7423. 6p. Acessado em 09 de fev. 2005. Online. Disponível na internet "http:// www.ipm.ucdavis.edu/PMG/PESTNOTES.html .

EMBRAPA. Psilídeo-de-concha. Colombo: Embrapa Florestas, 2004. 2p. (Boletim Técnico, s/n).
MCT. Brasil: campeão do eucalipto. Obtido via site de busca Google. Acessado em 08 de fev. 2005. Online. Disponível na internet: http://www.mct.gov.br/especial/genolyptus4.htm

SÁ, L.A.N.; WILCKEN, C.F. Nova praga exótica no ecossistema florestal. Jaguariúna: Embrapa Meio Ambiente, 2004. 3p. (Comunicado Técnico,18).

WILCKEN, C.F. et al. Ocorrência do psilídeo-de-concha (Glycaspis brimblecombei) (Hemiptera: Psyllidae) em florestas de eucalipto no Brasil. Piracicaba: Instituto de Pesquisas e Estudos Florestais, 2003. 11p. (Circular técnica, 201). 